\title{
Central do Brasil e o Melodrama
}

Lisandro Nogueira*

\section{Resumo}

O Cinema Novo, liderado por Glauber Rocha, edificou um estilo de cinema denominado "estética da fome". Sintonizado com a problemática nacional, elegeu um olhar crítico e polêmico, desprezou o melodrama e instituiu a criatividade em meio a carência. Central do Brasil retoma temáticas do Cinema Novo, junta-se ao melodrama e dialoga com o Cinema Novo. O resultado é a eclơsão de uma nova linguagem e uma nova visão para velhos temas.

Palavras-chave: cinema novo, Brasil, Nordeste.

\section{Introdução}

O filme de Walter Salles insere mais uma vez o cinema brasileiro no circuito internacional. Expressão da nossa realidade, nos expõe por meio de filmes que já fazem parte da história do cinema mundial, Deus e o Diabo na Terra do Sol (64), O pagador de promessas (62) e de filmes que tentam ser reconhecidos e adotados por um mercado pouco interessado em questões mais sérias.

O que interessa observar é Central do Brasil e sua proposta, comparando-o com filmes do cinema novo. Central do Brasil recupera e repõe uma tradição do cinema nacional? Há um abismo entre a tradição do Cinema Novo e a adesão de Walter Salles a um formato industrial? Vê-lo sob o prisma da comparação nos estimula a percorrer um pouco da estrada que se bifurcou em vários caminhos, propostas e interesses. Desta forma, não submetê-lo ao pêndulo infeliz da euforia ufanista ou da indiferença é a maneira mais sincera de se tentar compreendê-lo e posicioná-lo perante movimentos e filmes que alcançaram também, em determinada época, prestígio e respeito.

O mais importante, contudo, é compreender que tipo de visão o filme constrói sobre o país. Essa visão reafirma os pressupostos do

* Professor da Faculdade de Comunicação e Biblioteconomia da UFG e mestre pela Escola de Comunicações e Artes da USP.

Comun. Inf., v. 3, n. 2, p. 155-159, jul./dez. 2000 
Cinema Novo ou dilui suas propostas? O Brasil de Central do Brasil difere em quê de filmes como Os Fuzis e Deus e o Diabo?

OCinema Novo conseguiu articular, pela primeira vez, uma "imagem do Brasil": densa, alegórica e estimuladora do pensamento sobre os problemas e as oscilações históricas - foi sua contribuição mais consistente e duradoura. Víamos pela primeira vez a nossa fisionomia diversa e a miséria crônica. Depois das experiências críticas de Glauber Rocha, Ruy Guerra, Nelson Pereira, tornou-se difícil “esconder" o Brasil. Essas imagens denotavam um estado de coisas que até então somente a literatura e a música tinham formulado mediante "imagens"1 .

Mesmo que por outro viés, é possível afirmar que Central do Brasil repõe as perguntas formuladas nos anos 60: quem somos nós? Que Brasil emerge na dualidade tensa entre campo e cidade? Que imagens podem expressar nossa carência e nossa obsessiva busca por afeto e compreensão? As respostas dadas pelo filme a essas questões podem indicar a continuidade ou a ruptura com um projeto de cinema nacional formulado nos anos 50/60. A comparação é necessária tendo em vista as temáticas semelhantes retratadas: violência, o campo e a cidade, o nordeste.

\section{O Melodrama}

Central do Brasil mantém o carisma por intermédio dos nossos melhores atores e, à sua maneira, coloca o Brasil e os brasileiros na tela. A "imagem do Brasil", ampliada na tela de forma realista pelo Cinema Novo, é descartada e o melodrama é eleito como suporte da narrativa. A escolha do melodrama já o afasta irremediavelmente da escola cinemanovista. Para os cineastas do Cinema Novo, o gênero não é só um apaziguador de conflitos e conforto para a alma ingênua, mas é, acima de tudo, um entrave para o aprofundamento das questões. Isto porque, ansioso pela comunicação e pelo efeito rápido junto ao público, não permite a densidade, o eclodir de contradições, menosprezando a angústia humana com o riso e o choro fáceis. Quando Rosa e Manuel, em Deus e o Diabo, vivem a experiência religiosa, ela não acontece como um dado à parte, um ornamento da situação. Com Josué e Dora, a religiosidade é moldura, pano de fundo, de onde só se aproveita o ambiente exótico para o surto, desencadeando a cena seguinte que, banhada em água e açúcar, mostra a depuração humanista com a velha senhora má deitada no colo do menino bom.

Comun. Inf., v. 3, n. 2, p. 155-159, jul./dez. 2000 
Em Deus e o Diabo, a religião é vista com muita acuidade; podese depreender que há no Nordeste uma alienação no messianismo. A alegoria de Glauber Rocha vê uma luta ambígua: seguir Sebastião, o profeta do sertão, é uma forma de não lutar, de esperar a força divina, mas, ao mesmo tempo, o olhar do cineasta não imputa uma condenação. Há um respeito pela cultura popular e as contradições de seu interior. Walter Salles não se permite um olhar atencioso quanto à religião hoje no Brasil. Se é apenas moldura, adereço na narrativa, não quer enxergar o estágio mercadológico das práticas religiosas. $\mathrm{O}$ Cinema Novo, na sua opção em enxergar a totalidade, as ligações entre os eventos sociais, não deixaria de levantar a questão.

O melodrama de Central do Brasil também não permite a ambigüidade, pois preocupa-se em dar lição moral. É muito difícil narrar melodramaticamente sem cair no moralismo e dividir o mundo em certo e errado, maniqueísmo que revela uma adesão aos códigos de conduta da indústria de cinema americana. Esse código vigora em Hollywood desde 1920, com rebeldia esparsa aqui e ali. Ele diz: a) não se produzirão filmes contra os princípios morais do público; b) serão apresentados modelos corretos de vida, sujeitos apenas ao drama e ao entretenimento; c) a lei não será ridicularizada nem se poderá despertar simpatia por sua violação. $O$ filme segue essas normas. Não deixa de ser uma das senhas principais que o guindaram ao Oscar e ao restrito mercado americano para o filme estrangeiro-mesmo procedimento de $O$ que é isso companheiro?, de Bruno Barreto.

Desta forma, Dora é uma mulher quase assexuada. Num único momento que tenta se mostrar mulher, colocando o batom, se penteando, na busca da sedução do caminhoneiro, o diretor reprime o desejo, pois o homem, além de ser protestante, foge, retornando o abandono. É uma escolha moral. Para Dora está reservado o amor de um pai imaginário, projeto de amor-ideal no qual a sexualidade é uma carta fora do baralho, ponto para o primeiro código da indústria. Em Deus e o Diabo, a sexualidade transborda em poesia e desejo. A cena de Corisco seduzindo Rosa, com as bachianas de Villa-Lobos no fundo musical, é uma ode ao amor. Em Os Fuzis, a intensidade erótica do encontro entre um dos soldados e uma das moças do vilarejo mostra a efervescência do desejo em meio a uma situação limite de precariedade social.

O filme insiste em apresentar modelos corretos de vida. Dora é má, persona de índole cafajeste. O único sinal da origem dessa perso-

Comun. Inf., v. 3, n. 2, p. 155-159, jul./dez. 2000 


\section{8}

nalidade é a ausência do pai. O filme, encalacrado na escolha moral da correção, faz de Dora uma vítima que precisa percorrer o inferno do abandono e fugir dos algozes. Com isso, faz uma purgação da sua maldade. $\mathrm{O}$ anjo moralista, não por acaso uma criança, irá lhe mostrar o caminho da redenção que culmina com o transe numa sala de milagres. É exatamente o caminho contrário de Rosa e Manuel. Abandonados por uma situação social percorrem o sertão procurando uma saída: enfrentam a religião fanática, fogem, são seduzidos pelo cangaço, mas, num impulso vital, preferem correr em busca de outro destino. A cena final dos dois em desabalada carreira à beira-mar sugere um cinema que aponta os problemas, não camufla os conflitos e nem os transforma em vítimas.

Com Josué e Dora dá-se o contrário, o movimento é no sentido de individualizar os conflitos como se o contexto fosse mera moldura. $\mathrm{O}$ que importa é ação individual, o gozo narcísico em que tudo se resolve. A população com a qual se deparam são construções estereotipadas: os romeiros no caminhão são engraçados contando os seus cajus e o irmão mais velho de Josué faz a caricatura do nordestino com sua fala "abestada". Nesse ponto, por intermédio de Josué, o filme sinaliza para um cinema que privilegia e elogia o senso de oportunidade, a esperteza individual alheia ao sofrimento dos demais.

\section{Utopia e Fragmentação}

São contextos diferentes Central do Brasil, Deus e o Diabo e Os Fuzis, mas um aponta para o apaziguamento pelo humanismo, proposta ingênua porque veda os olhos para os problemas complexos; os outros, na sua alegoria, propõem o embate e a utopia de um projeto de nação que requer a ação proposta por Rosa e Manuel (a experiência). Walter Salles apresenta um projeto pronto para o Brasil, como se dissesse: - a questão é: “querer é poder”, numa infantilização das questões nacionais. Josué é o anjo que apresenta o campo como o local da pureza, da restauração, da solidariedade, contrapondo-se à nefasta vida urbana. Entretanto, tanto as mazelas da cidade como as do campo não são problematizadas. A cena do assassinato é gratuita e dispensa antecedentes e consequências. A morte de Gaúcho, motorista de caminhão, em Os Fuzis, acontece dentro de um contexto, tem causas, expõe feridas, e mostra que "aquém da transformação não há humanidade possível"2. O Cinema Novo recusa a idéia da pureza da

Comun. Inf., v. 3, n. 2, p. 155-159, jul./dez. 2000 
nação, sacralizada no périplo de Josué e Dora; recusa a noção da índole pacífica do povo brasileiro; recusa a visão amena do atraso e da pobreza. Central do Brasil tem um projeto de buscar uma nação, a "delicadeza perdida", porém dribla as questões cruciais. Se mostra :nalfabetos, não discute a educação (Josué, analfabeto, em nenhum momento é incentivado ou fala em ir para a escola); se mostra miséria, passa-lhe um verniz com a construção da caricatura do nordestino "pobre, porém decente"; se procura um Brasil real, o esconde na solução de um problema individual.

Walter Salles tem seus méritos ao valorizar os atores brasileiros, realiza um filme autoral, estampa uma visão de mundo, concilia opinião com mecanismos fáceis de interlocução com o público; é carismático e sedutor porque utiliza o melodrama e uma música consoladora. Sabe dosar senso comum com pinceladas de preocupação existencial, daí simpático e envolvente num primeiro olhar. A partir do segundo olhar, a ilusão de um cinema vigoroso cede lugar a um cinema superficial e limpo.

É uma obra pós-moderna, com a afirmação do cineasta profissional em choque com o cineasta intelectual; descarta o cinema como instância de reflexão crítica; instala um olhar fragmentado da realidade em detrimento da visão ampla. Falta-lhe a coragem de um olhar crítico, não domesticado, atrelado a um sabor poético que não inverta a realidade.

\section{Abstract}

The "Cinema Novo", leaded by Glauber Rocha, constructed a cinema style called "hunger aesthetics". Tuned with national matters, it chose a critical and controversial perspective, despised the melodrama and gave rise to creativity in a privation environment. The film "Central do Brasil" establishes a dialogue with Cinema Novo, revisits its motifs, and comes closer to melodrama. The result is the emergence of a new language and a new view for old themes.

Keywords: cinema novo, Brazil, Nordeste.

\section{Notas}

1. Xavier, Ismail. Cinema Novo, Cinema Marginal - o cinema moderno brasileiro. Rio de Janeiro: Cinemais, n. 4, 1997.

2. Schwarz, Roberto. O Pai de Família. São Paulo: Paz e Terra, 1978, p. 27.

Comun. Inf., v. 3, n. 2, p. 155-159, jul./dez. 2000 